\title{
EL RELATO AUTOBIOGRÁFICO: NARRAR LA EXPERIENCIA COMO EJERCICIO DE ESCRITURA DE SÍ MISMO Y CONSTRUCCIÓN SOCIAL DE LA REALIDAD
}

\author{
Carlos G. Juliao Vargas \\ Grupo de investigación Innovaciones educativas y cambio social \\ cgjuliao@gmail.com \\ htpps://orcid.org/ 0000-0002-2006-6360
}

Mucho de lo que cuento en primera persona como si se tratara de una autobiografia es pura mentira. Ahora, que esas mentiras puedan tener una cantidad de verdad dentro, es otra cosa (R. Montero).

RESUMEN / ABSTRACT

Desde el terreno de la filosofía como estilo de vida, y de la subjetividad social y la interpretación como quehacer investigativo, analizo primero los relatos autobiográficos en su relación con la acción social y sus sentidos, es decir, la subjetividad social. Luego, presento una reflexión sobre la reconstrucción de la experiencia personal durante el relato (y el papel que juega la memoria en dicho proceso), que culmina con la incorporación del mito, como forma de configurar la narración desde un saber colectivo de gran plasticidad. Termino presentando la utilidad metodológica del relato de vida en una investigación de corte praxeológico.

Palabras Clave: relato autobiográfico, filosofar, subjetividad social, investigación praxeológica.

\section{EL RELATO AUTOBIOGRÁFICO: NARRAR LA EXPERIENCIA COMO EJERCICIO \\ DE ESCRITURA DE SÍ MISMO Y CONSTRUCCIÓN SOCIAL DE LA REALIDAD}

From the field of philosophy as a lifestyle, and of social subjectivity and interpretation as an investigative task, I first analyze autobiographical accounts in relation to social action and its meanings, that is, social subjectivity. Then, I present a reflection on the reconstruction of personal experience during the story (and the role memory plays in this process), which culminates in the incorporation of myth, as a way of configuring the narrative from a highly plastic collective knowledge. I finish by presenting the methodological utility of the life story in a praxeological research.

KEYWORDS: Autobiographical story, philosophize, social subjectivity, praxeological research. 
$\overline{R M}$ En el conocido mito de Narciso, el ser humano, cautivo de su propia imagen, refleja la complejidad y el misterio que encierra la representación de sí mismo. Al mirarse en el agua, Narciso, a quien los dioses habían prohibido hacerlo, establece el primer autorretrato, imagen que lo conduce a la muerte. La escritura de sí, como el autorretrato (hoy sería la selfie), poseen una especial, abundante y compleja historia, en la que sobresale la importancia de hacer memoria, de reconstruir la propia imagen, desenterrando antiguos y olvidados yos; todo ello de un modo performativo y concreto, casi como en un ejercicio espiritual, que da cuenta de la propia existencia. Es claro que dibujar o escribir la imagen de sí mismo, como conjuro y exorcización de la realidad ha cumplido, desde sus inicios, una tarea de interpretación (testimonial) del sujeto, de desvelamiento del sentido, el trascurso y la finitud de la existencia. El relato de vida, ¿es la escenificación de una trayectoria vital con el propósito de un trabajo objetivo? O, al contrario, ¿es una reconstrucción personal de la propia historia tomando su sentido de la subjetividad? O, ¿la cuestión no puede plantearse como oposición de lo objetivo y lo subjetivo?

Para entender hoy el propósito y los modos de escritura personal-sean realizados de forma individual o como parte de un proceso formativo o investigativo-creo que es necesario, más allá de cualquier otra consideración, comprender lo que ha significado en la historia el fenómeno de la escritura de sí. Y para ello es esencial abordar la filosofía grecorromana, como Hadot (2006), Nussbaum (2003) y Foucault (2001) la presentan, insistiendo en que cualquier reflexión sobre la escritura de sí debe partir del hecho de que la filosofía antigua es sobre todo un estilo de vida, y no tanto la construcción de un sistema de ideas. La filosofía, desde sus orígenes, pero cada vez más con los helenísticos postsocráticos -cínicos, epicúreos, estoicos- se había centrado en definir una cierta técnica de vida (tekhne tou biou) como arte o proceso reflexivo y crítico de la existencia. Foucault precisa, de modo cuidadoso y de acuerdo con Hadot y Nussbaum, que la filosofía cumple una función terapéutica: curar o cuidar del alma (psukhês epimelêteon). Así surge el imperativo del cuidado de sí mismo, expresión que traduce un concepto griego complejo, pero muy extendido, el de epimeleia heautou (cura sui, en latín), que incluye todo un corpus caracterizado por formas de razonamiento y ejercicios, voluntarios y personales, inseparables del modo de vida filosófico. Foucault lo aclara así: "Ninguna técnica, ninguna habilidad profesional puede ser adquirida sin ejercicio; no podemos aprender el arte de vivir, el biou techne tou sin una askesis que debe ser entendida como un entrenamiento de sí por sí mismo" (2001, p. 1236). Y si bien todo esto es claro en los antiguos, hay que reconocer que muchos otros pensadores (filósofos, artistas, intelectuales) han practicado ejercicios de escritura de sí (Montaigne, Rousseau, Nietzsche, Baudelaire, Goethe, Gómez Dávila, Fernando González, entre muchos otros) queriendo hacer de la vida una obra de arte, mostrando como la subjetividad invita a configurar este conocerse, a preocuparse y ocuparse de sí mismo. Es en lo que insisto en mi libro Tomar la filosofía en serio:

(...) me importa presentar una comprensión del saber filosófico olvidada porque no es "útil para la vida productiva": se trata del ejercicio filosófico que suscita el pensar por sí mismo, el examen de sí y la elaboración de narrativas sobre quiénes somos y sobre la realidad que nos rodea; lo que normalmente se le cuestiona es 
que su sentido solo se encuentra en el ejercicio mismo del filosofar, en el proceso y no en el resultado. Se trata de la filosofía como estilo y modo de vida (Juliao 2019, p. 21).

Por otra parte, en las últimas décadas, las ciencias sociales han revalorado significativamente el estudio de las creencias, los valores, las opiniones, el ethos personal y colectivo, así como el saber de sentido común; y con ello han vuelto a situar, en el campo de la investigación social, la importancia de las llamadas técnicas de sí (relato autobiográfico, confesiones, diarios, cartas, entre otras). El saber que les corresponde no es solo de carácter individual, si bien sus custodios son los individuos, en tanto permite también la construcción social de la realidad y del mundo. Igualmente permite hacer un bosquejo del campo de la subjetividad social, ángulo desde el cual se puede pensar la realidad social. Toda esta reorientación de las ciencias sociales tiene que ver también con los temas de la complejidad de las sociedades contemporáneas, con la aparición de nuevas subjetividades y con las formas actuales de construir los vínculos sociales. De algún modo, todo ello muestra que los actos humanos, la praxis, no son independientes del pensamiento, ni de la valoración o la imaginación. Por eso, esta reorientación y desafío que enfrentan hoy las ciencias sociales está asociado a ese interés praxeológico que quiere volver objeto de estudio el vínculo existente entre la acción banal y cotidiana de los individuos y grupos, y el pensamiento.

Delory-Momberger (2015), en la introducción a su libro, plantea la emergencia y desarrollo de lo que llama "condición biográfica" enmarcada en el contexto actual de individualización y subjetivación:

La acentuación de estas formas de socialización está ligada a las transformaciones societales que conlleva el pasaje de sociedades nacionales, industriales, centralizadas, a formas de sociedad cuyos organismos políticos, sociales, económicos, pierden su centralidad, cuyas instituciones ya no tienen la misma capacidad de integración, y que requieren cada vez más de individuos que encuentran en sí mismos las fuerzas propulsoras de su acción en el seno del espacio social (p. XVIII).

Hoy el individuo se ha convertido en la institución central de la sociedad: en una sociedad mercantilizada el individuo, convertido en su propio producto, "se compra una vida" (Bauman 2007), y "debe aprender a considerarse él mismo como un centro de decisiones, una oficina de organización de su propia existencia” (Beck 2003, p. 291). Delory-Momberger (2015) lo sintetiza así:

En la sociedad industrializada, la socialización pasaba por la integración del individuo en los espacios sociales e institucionales (la familia, la escuela, el mundo laboral, etc.). En la sociedad de la modernidad avanzada, es tarea del individuo integrar en su biografía las esferas de lo social en un movimiento de apropiación y de construcción personal (...) En consecuencia, cada uno es reenviado a la construcción reflexiva de su propia existencia, a su biografía -entendida aquí no como el curso real, efectivo de la vida, sino como la representación construida que se hacen los actores de ella-y de su capacidad de biografización de los ambientes sociales (págs. XXVIII-XXIX). 
Si admitimos que explorar el sentido y los significados a partir de los cuales surge la acción representa un momento analítico, otro momento será aquel durante el cual el investigador se pregunta sobre cómo se forman y reconstruyen estos contextos sociales de sentido en los cuales los individuos desarrollan sus vidas, incorporándolos, y al mismo tiempo, modificándolos. ¿Cómo entender los procesos mediante los cuales los individuos se apropian de ciertas ideas, patrones culturales, creencias, valores, imágenes y saberes ordinarios de su época en detrimento de otros? Los procesos educativos de socialización, en sentido amplio, ofrecen respuestas a estas preguntas.

La comprensión de la sociedad a partir de la subjetividad social supone considerar el punto de vista del individuo en tanto agente activo, es decir actor y autor, pero también la concepción de la realidad social como una construcción permanente y nunca terminada. Y, desde un punto de vista metodológico, esto supone revalorizar la interpretación. La narración autobiográfica es un terreno fértil para ello, pese a la dificultad que existe para aceptar este método, dado que las tradiciones sociológicas legitimadas durante mucho tiempo van en la dirección opuesta. Entre otros, los prejuicios relacionados con la obtención de la verdad y las fantasías sobre una realidad objetiva y externa, que en el fondo se sustentan en una idea muy academicista de la filosofía, olvidando que ésta es, ante todo, algo práctico, un estilo o forma de vida. ¿Es posible entonces, que las filosofías contemporáneas incluyan en su comprensión de la filosofía esta dimensión práctica? ¿O solo queda recurrir a los antiguos y algunos modernos para ponernos en la ruta de las prácticas filosóficas narrativas que cambiarían nuestra forma de vivir?

Desde este terreno de la filosofía como estilo de vida, y de la subjetividad social y la interpretación como quehacer investigativo, quiero primero analizar los relatos autobiográficos en su relación con la acción social y sus sentidos, es decir, la subjetividad social. Luego, presento una reflexión sobre la reconstrucción de la experiencia personal durante el relato (y el papel que juega la memoria en dicho proceso), que culmina con la incorporación del mito, como forma de configurar la narración desde un saber colectivo de gran plasticidad. Termino, presentando la utilidad metodológica del relato de vida en una investigación de corte praxeológico.

\section{Los relatos autobiográficos}

Las razones para escribir un relato autobiográfico pueden ser muchas y variadas: hablar de sí para uno mismo o para los demás, conocerse, entender la propia personalidad, volver sobre el itinerario personal, testimoniar una experiencia particular, explicarse, exponer sus opciones vitales, confirmar eventos importantes, mejorar la acción, entre otras. Es lo que expresa Gide en su autobiografía: "Que suene la trompeta del juicio final cuando quiera; estaré, con este libro en mi mano, presentándome ante el juez soberano. Diré en voz alta: Aquí está lo que hice, lo que pensé, lo que fui. Dije lo bueno y lo malo con la misma franqueza" (1956). O como lo expresa un pequeño diálogo en la película Diario de una ninfómana (2008), donde Geraldine Chaplin dice 
- Los que escriben un diario es porque se sienten solos.

- No es verdad, es porque tienen algo que contar. Porque su vida es diferente, y aunque nunca lo confiesen, siempre esperan a que alguien lo descubra y lo lea a escondidas para conocer la verdadera personalidad del autor ${ }^{1}$.

Los relatos de vida o autobiografías están arraigados en la experiencia humana, y como tales, representan una fuente para reconstruir la praxis y la vida ya lograda; no son el actuar en sí mismo, sino una versión que el autor sugiere de su acción en el pasado. Porque la vida se va haciendo al contarla y la memoria se precisa y consolida con la escritura. Cuando un narrador cuenta fragmentos de su vida, se accede a un relato sobre ciertos procesos y relaciones sociales puestos en acción en una vida concreta, relato que invita a una interpretación que puede hacerse al menos en dos niveles. El primero corresponde a las interpretaciones que se realizan como interlocutor del relato y basados en el sentido común. El segundo es lo propio del proceso interpretativo: simultáneamente, se lo interpreta a partir de las preguntas teóricas que se le plantean al relato.

Una de las características básicas de los relatos autobiográficos es que hablan de experiencias vividas; son también como instrumentos que ayudan a encontrarle sentido a la vida. El narrador las cuenta, las interpreta y las conecta entre sí, y a través de ellas, los otros actores que aparecen siempre se presentan desde la experiencia del narrador. De esta manera, el narrador construye un personaje central, un héroe (Piña 1989). Pero, como afirma Lejeune, "lejos de estructurarse en forma de historia, la memoria posee una riqueza y una complejidad que el relato lineal sólo puede traicionar" (1971: 77), de modo que el orden en que los acontecimientos aparecen en la memoria no es el mismo en el que se vivieron; de ahí los esfuerzos de ciertos autores por ser coherentes de sus relatos (como por ejemplo Rousseau o Stendhal). May resume esto así:

La verdad es que la condición primera de la autobiografía es la de hacer frente a un dilema irresoluble: o bien someter la caprichosa proliferación de los recuerdos a un determinado orden, faltando con ello a la veracidad, o bien renunciar a un orden que no existe en la experiencia real y faltar así a la inteligibilidad. Es comprensible que el autobiógrafo, que por lo general escribe para un lector, opte casi siempre por la primera de estas opciones (1979: 76-77).

Otra característica central es el hecho de que se trata de relatos, lo que implica que la persona que cuenta le imprime una estructura propia a su narración. Una semiestructuración dada desde afuera (como, por ejemplo, hecha por el investigador que sugiere o requiere de dicho relato autobiográfico), sería contraria a la estructura narrativa del autor. Esto solo podría darse antes del relato, para incitar al narrador a comenzar su construcción personal desde un espacio o momento de su vida.

El narrador reconstruye el hilo de su historia a través de experiencias vividas que él considera socialmente significativas y, al mismo tiempo, a través de este hilo,

Frase tomada de https://www.mundifrases.com/s-pelicula/diario-de-una-ninfomana/ 
asume una cierta lealtad consigo mismo. "Observar el esfuerzo de rememorización de un sujeto que se esfuerza por reconstruir el hilo de su itinerario biográfico es una fuente de información sobre lo que tiene sentido para él" (Bertaux 2005: 82). Al elegir y articular los momentos vividos para narrarlos de modo comprensible para el otro, el narrador no solo explora su memoria, sino que también indaga sobre el contexto sociocultural en el que estas experiencias adquieren sentido, provocando la conexión de eventos y situaciones cotidianas. Por lo tanto, la estructura narrativa no podría ser impuesta desde afuera: no hay una verdad que deba surgir en la narrativa autobiográfica, sino solo experiencias elegidas en la memoria y conectadas entre sí.

Finalmente, se puede identificar un tercer rasgo característico de estos relatos: es el hecho de que son socialmente significativos. La estructura narrativa hace que la experiencia sea entendida por el otro. En otras palabras, hay una especie de traducción de la dimensión íntima de las experiencias a formas socialmente compartidas y depositadas en el lenguaje ${ }^{2}$. El hecho de situar esta experiencia en el lenguaje (entendido como acción, no como estructura) hace que pierda su dimensión individual y privada, transformándola así en una expresión singular de lo social. De esta manera, el relato autobiográfico no solo se deriva del campo de la experiencia, sino que también se vuelve socialmente significativo por el hecho de que cualquier experiencia elegida se ha traducido a un contexto sociocultural, a través del lenguaje, lo que reduce la dimensión de lo vivido, pero permite la comunicación. La narrativa de la vida describe tanto la vida interior del narrador como los contextos sociales que ha atravesado.

Como resultado, estos relatos no se adentran en la dimensión íntima de la vida, sino que ofrecen un discurso construido en un contexto de sentido socialmente compartido, y sobre la base de un conjunto de saberes comunes. Cumplen varias funciones, en particular la reconstrucción del tiempo mediante la conciencia de la biografía, la acción de producción de saberes mediante la construcción conjunta de reflexiones y la relación del curso de la vida con la propia relación con el conocimiento ${ }^{3}$. De acuerdo con esta forma de ver las cosas en los relatos, el individuo tiene espacio solo como una expresión singular de lo social (Chanfrault-Duchet, 1988). Incidentalmente, esta interpretación

2 Lo íntimo se refiere al hecho de que "soy el único que sabe lo que sentí"; es la experiencia interior. Lo íntimo es esa experiencia que va más allá de lo que las palabras pueden expresar. De hecho, cuando esta experiencia es nombrada de alguna manera, lo que se ha sentido pierde su carácter íntimo, se convierte en social precisamente al ser nombrado con una o más palabras que el otro puede entender. socialmente. Es en este sentido que esta versión de la palabra íntimo no tiene relación alguna con lo que estamos acostumbrados a oponer al sentido de lo público o lo que no se debe decir públicamente. En este contexto, lo íntimo significa toda la complejidad de la experiencia vivida que no se puede transmitir al otro, y eso porque la simple transmisión verbal la transforma y la reduce.

3 Hay que tener en cuenta el doble sentido de la noción de tiempo en un relato de sí: el tiempo se percibe y evalúa subjetivamente, tanto en el curso de los acontecimientos como en la construcción social del suceso. 
destruye el concepto erróneo de la posible mentira, que existiría solo a partir de la singularidad de la vida del narrador, pero no de la singularidad social del relato.

May (1979) plantea que el relato autobiográfico puede asumir cinco formas diferentes cuando el orden cronológico se cambia por otros modos de ordenar la narración ${ }^{4}$ :

a. Orden temático: cuando se agrupan los recuerdos a partir de temas tales como defectos, virtudes, amigos, enemigos, entre otros. Ejemplos de ello serían $\mathrm{Mi}$ vida (Gerolamo Cardano), tal vez una de las primeras autobiografías modernas que narra lo que era un sabio (filósofo y matemático) del siglo XVI, y Confesiones de un autor dramático (H.R. Lenormand), que sorprende porque no es frecuente que un escritor (en este caso un dramaturgo francés bastante famoso) se atreva a decir, de sí mismo, la verdad desnuda, la verdad en sus aspectos buenos y malos.

b. Orden asociacionista: cuando el autor se deja llevar por la asociación de ideas, con recurrentes digresiones. Caso claro de ello es La autobiografía de Benjamín Franklin, que al mismo tiempo que narra su vida plagada de las anécdotas y enseñanzas de su larga existencia, inacabada por definición, como el mundo en el que se había gestado; la obra que inicia como una carta a su hijo y continua como un testimonio para sus conciudadanos, presenta la tradición cultural calvinista puritana y el espíritu de la Ilustración, así como la conciencia del cambio social y económico que se generaba en los albores de la industrialización en Norteamérica; la obra terminó convirtiéndose en un estilo de vida para muchos.

c. Orden lógico o didáctico: cuando se organizan los recuerdos buscando una interpretación sobresaliente y si es el caso, educativa. Ejemplo de este tipo de autobiografías serían Si la semilla no muere, de André Gide (1956), que en la primera parte narra su infancia y recuerda nostalgias familiares, y en la segunda, mucho más corta, explica el descubrimiento de su homosexualidad durante su viaje a Argelia (donde conoció a Oscar Wilde); también habla sobre la pederastia, lo que escandalizó bastante al público de la época. Otro ejemplo son las Memorias de una joven formal, de Simone de Beauvoir (1967), en la que nos cuenta quién fue ella, pero también, y, sobre todo, la época en la que vivió, en sus dimensiones sociales, culturales y políticas. Lo mismo podría decirse de Vivir para contarla de García Márquez (2002).

$4 \quad$ Pese a ser bastante amplia, esta tipología de May no agota en absoluto las posibilidades de la autobiografía. Por ejemplo, está el conocido texto Roland Barthes por Roland Barthes, autobiografía fragmentada donde los recuerdos se organizan siguiendo un orden alfabético. O las Memorias de Casanova que siguen un orden espacial, recordando lugares significativos para el autor por su valor sentimental o simbólico. O De mi vida, de Nietzsche, que podría considerarse una guía de lectura de las obras del autor. 
d. Orden obsesivo: el que muestra las obsesiones y estados mentales del autor. Un ejemplo claro son los cuatro libros de La Regla del juego, de Michel Leiris, donde la memoria se guía con frecuencia por la mera analogía fonética, a la manera de un malabarismo de los recuerdos ligados al lenguaje, con los que el autor se va retratando sin retoques y, al tiempo, refleja significativamente la condición humana. El mismo título contiene cierto ardid: en francés, las palabras jeu (juego) y je (yo) se pronuncian del mismo modo: con ese juego de palabras Leiris expresa su gusto tanto por lo lúdico de la escritura (y los convencionalismos que la limitan), como por la observación de sí mismo, origen y finalidad de su ejercicio literario.

e. Orden ad hoc: aquel que se adopta ya no para contar el proceso de una vida, sino para reflejar algunos aspectos de esta. Caso claro serían las Antimemorias de André Malraux (1992), una larga reflexión, donde su autor recrea sus encuentros con personajes como Nehru, De Gaulle y Mao, y se cuestiona sobre la muerte, la condición humana, el sentido del arte y la existencia de Dios, entre otros temas.

Así, el relato autobiográfico puede asumir diversas formas literarias, que condicionan el momento elegido para hablar de sí mismo, la duración y la frecuencia, la elección de la persona gramatical, los tiempos verbales. Veamos, a modo de ejemplo, como refleja esto el comienzo de las Memorias de una joven formal:

Nací a las cuatro de la mañana el 9 de enero de 1908, en un cuarto con muebles pintados de blanco que daba sobre el Bulevar Raspail. En las fotos de familia tomadas el verano siguiente veo a unas jóvenes señoras con vestidos largos, con sombreros empenachados de plumas de avestruz, señores con ranchos de paja y panamás que le sonríen a un bebé: son mis padres, mi abuelo, tíos, tías y soy yo. Mi padre tenía treinta años, mi madre veintiuno, y yo era la primogénita. Doy vuelta una página del álbum; mamá tiene entre sus brazos un bebé que no soy yo; llevo una falda tableada, una boina, tengo dos años y medio y mi hermana acaba de nacer. Sentí celos, según parece, pero durante poco tiempo. Por lejos que me remonte en el tiempo encuentro el orgullo de ser la mayor: la primera. Disfrazada de Caperucita Roja, llevando en mi cesta una torta y un tarro de manteca, me sentía más interesante que un lactante clavado en su cuna. Tenía una hermanita: ese bebito no me tenía (Beauvoir 1967: 5).

Ahora bien, los estilos literarios más frecuentes son: a) La autobiografía que asume la forma de una narrativa más o menos cronológica recorriendo los diferentes períodos de la vida del autor, desde su nacimiento hasta el momento en que se lanza a su proyecto de escritura; b) el diario (diario íntimo o diario de viaje) informa día a día los acontecimientos vividos por el autor; por lo general, especifica la fecha y, a veces, el lugar, y el relato suele ir acompañado de comentarios; c) las memorias que relatan la vida del autor, pero insistiendo en los acontecimientos históricos de los que fue testigo o actor; d) la correspondencia que también revela la existencia de una persona porque relaciona los eventos que vive y expresa sus sentimientos, emociones, ideas y reacciones. Algunos autores deciden contar su vida inventando un doble, mezclando sus recuerdos con la 
ficción; en ese caso se habla de novela autobiográfica, en la que identidad entre autor, narrador y personaje desaparece. Así, Jules Vallès cuenta la vida de Jacques Vingtras en una trilogía publicada entre 1879 y 1886: El niño, El soltero, El insurgente. Amélie Nothomb, en Stupeur et tremblements (1999), que presenta como una novela, se inspira en su propia vida en Japón para imaginar las aventuras del narrador en una compañía japonesa. También se podría aquí mencionar a El amante de Marguerite Duras.

Existen otros tipos de escritos más o menos similares a la autobiografía: a) La historia de vida, bastante frecuente en nuestro tiempo en los estudios humanos y sociales: una persona cualquiera, durante una entrevista, cuenta su vida a un investigador, escritor o periodista, quien le entrega un formato escrito para hacerlo ${ }^{5}$; b) las entrevistas que también pueden tener una dimensión autobiográfica (así Marguerite Yourcenar recuerda su infancia, su carrera como escritora, su tiempo, durante las entrevistas con el periodista Mathieu Galey, publicadas bajo el título Les Yeux ouverts, en 1980); c) el cómic que también se ha interesado en lo autobiográfico (ejemplos de ello son Marjane Satrapi, Persépolis; Art Spiegelman, Maus; Joann Sfar, Harmonica, historias gráficas donde los autores relatan su propia existencia y sus experiencias -casos de Satrapi y Sfar- o las de sus familiares - caso de Spiegelman).

Con todas estas perspectivas, es necesario ahora preguntarse acerca de aquellos procesos que entran en juego en la producción de una autobiografía. Es común que el peso de la objetividad del sociólogo, ligado a la estrategia de aislar los fenómenos, lo lleven a observar el relato en sí mismo, lo cual es más fácil si se considera como un texto separado del sujeto que lo construyó y olvidando el contexto de interacción en el cual fue construido. Sin embargo, hay que analizar en detalle los procesos que entran en juego en esta situación particular que corresponde a un individuo que habla de sí mismo ${ }^{6}$. Porque "la realización de un relato de vida depende de la imagen que uno tiene de sí mismo, que se debe poner en palabras si se quiere compartirla. Y las palabras que uno elige para dirigirlas al otro, se extraen de narraciones del contexto, rumores, poemas, mitos y prejuicios" (Cyrulnik 2012: 13).

Este tipo de reflexión permitirá evaluar la relevancia metodológica del relato autobiográfico más allá de los modos; también asegurará de que pueda ubicarse en un nivel que le impida pensar en ello de acuerdo con la cuestión de la mentira y la verdad, que quedan acá fuera de contexto porque "la vida no es la que uno vivió, sino la que uno recuerda y cómo la recuerda para contarla” (García Márquez 2002).

5 Daniel Bertaux afirma que "desde el momento en que aparece la forma narrativa en una conversación y el sujeto la utiliza para examinar el contenido de su experiencia vivida, entonces decimos que se trata de un relato de vida" (2005: 36).

$6 \quad$ Pienso que Chanfrault-Duchet (1988) es quien ha realizado el análisis más detallado de esto, desde la perspectiva del sistema interaccional establecido entre el narrador y quien realiza la entrevista (págs. 26-31). 


\section{Los juegos de la memoria en los relatos autobiográficos}

La invitación a contar la propia historia o parte de ella remite a un esquema lingüístico aprendido desde la infancia, como es el caso del relato: desde niños aprendemos a contar escuchando historias, leyendas, cuentos y relatos, pero también contando nuestra propia cotidianidad. Esta invitación no solo abre el esquema narrativo, sino que también impulsa una motivación estética (Franzke 1989). Por ello las historias de vida también pueden considerarse productos literarios en los que la ficción se entreteje sobre la base de un criterio estético. Esta forma de construir la ficción también da cuenta de la realidad social.

Si tomamos en cuenta el montaje estético del relato autobiográfico, no podemos concebir al narrador como un testigo pasivo de los acontecimientos, como un simple depositario de un saber que se transmitirá al otro, sino también como un actor capaz de actuar y de construir un discurso sobre su sociedad y su propia vida en ella. Por lo tanto, no podemos considerar al narrador como una especie de "banco de datos" (Chanfrault 1987) que está abierto y que emite la información buscada. El narrador realiza un verdadero montaje de su texto. Sin embargo, esto no debe interpretarse como una intención de engañar, de manipular; más bien, significa que, al relatar su vida, el individuo la replantea; de manera general, podemos decir que se convierte así en el "sociólogo de su propia biografía" (Vrancken 1986: 315), porque busca establecer conexiones entre los hechos, construye sus propias secuencias de eventos, seleccionando algunos y excluyendo otros, cuestionándose sobre las motivaciones de sus propias acciones.

Este acto de repensar la propia historia es un proceso que sucede en el momento presente, pero se trata de un presente que contiene un pasado. Así, el pasado se cuenta en referencia a las condiciones actuales, pero también con relación a patrones o esquemas incorporados en otros momentos; como resultado, el narrador puede repensar su biografía en relación con los esquemas cognitivos incorporados posteriormente a los eventos relatados, pero anteriores al momento presente en el que construye su narración.

Esto es típico del relato autobiográfico y no hay razón para interpretarlo de modo negativo o como un defecto de los relatos. Al contrario, es una de sus riquezas que nos permite acercarnos a un presente que anticipa el futuro, un presente que conlleva el movimiento y, por lo tanto, el devenir, es decir, lo que aún no ha ocurrido, pero que ya está potencialmente en la narrativa: el potencial del relato consiste, por lo tanto, en que anuncia la forma que podrían adquirir las acciones del futuro próximo, aquellas que aún no se han ejecutado, pero que ya pueden ser concebidas y nombradas (Zemelman 1997: 21). Incluso si la narrativa se refiere a acciones pasadas, el recordarlas en el presente, son reconstruidas a través del lenguaje, lo que hace posible anticipar el futuro, las acciones por venir.

Esta reconstrucción de la acción puede interpretarse de acuerdo con cuatro ejes de análisis que terminan convergiendo entre ellos de modo recursivo. Uno es la concepción estética (teatralización) del montaje del relato. Otro está relacionado con los procesos de la memoria y el tercero es el resultado de los procesos de socialización. Finalmente, el último viene de la autoconstrucción que hace de sí mismo el narrador. 
Con respecto a los procesos de memoria y recuerdo, las teorías señalan que las situaciones captadas pasan por transformaciones en el momento de retroceder en la memoria, en el proceso de almacenamiento, así como en el momento de su reproducción como recuerdos. Según Cabanes, la memoria no está ausente en la construcción de la realidad: "La memoria está hecha de un pasado perdido y reencontrado para permitir que el futuro tenga lugar. El relato está del lado de lo que puede ocurrir" (1996: 65).

En cuanto a la reconstrucción de la experiencia, producto de una socialización que aún no termina, hay que decir que los individuos nunca estamos totalmente terminados (Elias 1990). A lo largo de nuestras vidas, continuamos acumulando experiencias y nuevos conocimientos que pueden tomar la forma de interpretaciones alternativas del mundo. Como resultado, las interpretaciones que hacemos de un acontecimiento en diferentes momentos de la vida no son necesariamente idénticas, porque los patrones interpretativos cambian durante cada biografía.

Esta dinámica de la memorización / recuerdo, pero también de la socialización incompleta, tiene una esencia temporal. A su vez, las historias de la vida están inscritas en el tiempo, porque hacen referencia permanente al recuerdo de imágenes y marcas del pasado, para devolverlas al presente. Como resultado, la reconstrucción de la acción es algo específico del relato autobiográfico, y antes de eliminar su valor sociológico, debe señalarse que esta reconstrucción de la acción, gracias a su traducción al lenguaje, muestra los laberintos de la construcción social de la realidad.

Estas reconstrucciones de la experiencia también pueden interpretarse referidos a la identidad personal; es decir, como procesos de "armonización retrospectiva" de la historia personal (Franzke 1989), que se explican por el deseo del narrador por presentar una identidad unificada a quien lo escucha o lee. Debido a las discordancias inherentes de cada biografía, el narrador se ve a sí mismo en la obligación de presentarse ante el otro como único, sin contradicciones; esto, por supuesto, solo puede ocurrir en la reconstrucción de la identidad narrada, porque en la experiencia, es difícil para el individuo ser único (Kaufmann 1996). Cada individuo es capaz de construir más de una identidad de sí mismo y éstas siempre se presentarán de forma monolítica, pero en diversas situaciones o contextos. Esto es posible gracias a la heterogeneidad existente en cada narrador (fruto de la complejidad de los procesos de socialización o de incorporación del saber ordinario), y le da la posibilidad de cambiar su identidad e incluso de negociar con sus "otras identidades".

En síntesis, la reconstrucción de las experiencias pasadas, en el momento de ser narradas, entra en relación con diversos fenómenos:

- La motivación estética que guía al narrador;

- La memoria que reconstruye la experiencia tal como se recuerda;

- El proceso de recuerdo que reconstruye la experiencia guardada en el momento de recordarla para relatarla;

- Los procesos de socialización que ocurren a lo largo de la vida, y siguen sedimentando experiencias y saberes. Como resultado, el individuo cambia 
sus referentes para interpretar su pasado y presente a lo largo de su vida. Al repensar la historia al momento de contarla, puede observarla desde una posición externa y cuestionarla a partir de los nuevos referentes que ha incorporado después de la experiencia en cuestión;

- La armonización retrospectiva mediante la cual el narrador quiere presentarse como único frente a los demás, y que es también otra forma de reconstrucción de la experiencia narrada;

- El esquema narrativo que impone un orden secuencial y reduce el nivel de caos de la experiencia; omite eventos, impone un orden consecutivo a los elegidos, incluso si varios de ellos tuvieron lugar simultáneamente. Este orden secuencial es parte de esa búsqueda para hacer que la historia sea comprensible.

De esta manera, para la sociología, las historias de vida no son un método para llegar a la verdad, sino expresiones singulares de vidas inscritas en la historia, mediante las cuales las personas, sin saberlo, reconstruyen la realidad a través del lenguaje y su memoria. La historia de la vida es un invento, es una construcción social permanente, pero se produce en el marco social de la vida cotidiana y no en el mundo de la fantasía. De ahí su valor como expresión de un fragmento de lo social y su potencial para dar forma a la acción futura.

\section{La narración de la historia contada}

En el punto anterior nos hemos centrado en los procesos que producen la reconstrucción de la experiencia en la narración actual, es decir, las razones por las cuales la experiencia se reconstruye durante la narración. Ahora propondremos una interpretación de cómo se reconstruye la experiencia narrada.

La reconstrucción de la experiencia se lleva a cabo gracias al ejercicio espontáneo y necesario ${ }^{7}$ realizado por el narrador para dar una nueva forma a los eventos del pasado, basándose en los esquemas interpretativos disponibles para él en el presente. Este ejercicio no planificado es el resultado de la introducción de acontecimientos vividos, experiencias narradas, en un conocimiento colectivo que reconoce un vínculo significativo con la experiencia en cuestión. De esta manera, la historia adquiere una estructura, se configura de acuerdo con este conocimiento colectivo.

Con frecuencia, la introducción de la experiencia pasada en una nueva estructura representa una especie de fabulación propuesta sin que el narrador lo sepa. La fabulación es el proceso que sigue espontáneamente el narrador cuando organiza sus experiencias como parte de una fábula conocida. Las fábulas añaden imaginación a la historia de

Esta es una condición necesaria porque la experiencia toma la forma (o la falta de forma) de lo experimentado, mientras que la narrativa adopta una forma lingüística. 
las prácticas vividas. Pero esta imaginación es parte de una memoria colectiva, ya que las prácticas son las experiencias vividas por el narrador. Desde un punto de vista metodológico, la fabulación porta significados sociales que revelan el contexto social. Toda fabulación habla de un espacio social, relaciones entre los grupos sociales que lo componen, actores y sus roles, valores y normas sociales (Vrancken 1986: 315-324). El narrador adopta una fábula específica que incorpora significados sociales relevantes para comunicar la experiencia que está contando.

Es en este sentido que la fabulación puede compararse, según Vrancken, con una forma de mito, que tiene la virtud metodológica de resaltar las claves para la interpretación. Interpretar las narraciones a partir de estos mitos, que no son visibles a primera vista, implica asimilarlas a formas estructurantes que contienen significados sociales. A través de los mitos, el relato inscribe la experiencia individual en el conocimiento compartido al que se reconoce la capacidad de transmitir una imagen de una parte de lo social. Como resultado, el mito es analíticamente una mediación entre la memoria colectiva y la experiencia individual (Chanfrault-Duchet 1995). En este contexto, el mito adopta el papel de una especie de metáfora colectiva que preserva y perpetúa una memoria común, un pasado colectivo. Enfoca imágenes y episodios de una comunidad (Vrancken 1986: 315). El mito funciona como una serie de saberes de una comunidad o un grupo social, extendido o pequeño.

Por eso, el mito le permite al narrador comunicar su experiencia en términos sociales, es decir, situarla en el nivel de las representaciones condensadas en el imaginario y en la memoria colectiva. Como resultado, el mito también desempeña el papel de mediación entre la experiencia vivida y su narración. Parafraseando a Michel Maffesoli, se podría decir que el mito se convierte en el "formato" de la biografía contada.

De esta manera, por este conocimiento colectivo, el individuo se convierte en un sujeto inscrito en la historia. El narrador utiliza el mito inconscientemente como una manera de reflejar su experiencia en el mundo, ubicándola en un contexto social al que pertenece. En última instancia, los mitos articulan lo individual a la sociedad.

Si el mito permite organizar la historia de una vida de acuerdo con una historia conocida, al insistir en ciertos actores, ciertos roles y un futuro, también se debe tener en cuenta que esta historia está frecuentemente atravesada por lo que algunos autores llaman las "figuras matriciales" (Chanfrault-Duchet 1995, págs. 12-21), es decir, figuras que marcan la narración de una biografía repetidamente. Estas son ideas fuerza que el narrador presenta como rectificaciones de su propia vida (incluso si no lo hace de manera explícita o consciente), ideas que han guiado al sujeto durante su vida. Estas ideas fuerza pueden entenderse en la perspectiva schutziana como explicaciones de las motivaciones para el futuro, gracias a las cuales el sujeto pretende dar sentido a su acción. El investigador solo puede resaltar estas figuras aplicando una actitud hermenéutica hacia el texto.

Ejemplos de este recurso son las figuras de la búsqueda de la diferencia, la pérdida, el triunfo o fracaso personal o el deseo de superación personal. Técnicamente, descifrar el mito y la figura que estructuran una narración, supone encontrar las claves o ejes de interpretación del texto, incluso si desde un punto de vista metodológico, es descifrar 
los contornos del sistema de significado en el que se apoyó el narrador y en el que sus acciones adquieren sentido. La estructura narrativa invertida por un mito y atravesada por una figura solo tiene sentido si se interpreta con referencia a los diversos contextos y grupos sociales a los que se refiere el personaje de la narrativa a lo largo de su vida.

En síntesis, interpretar las historias de vida nos obliga a enfrentar el desafío de descubrir estos mitos y figuras matriciales que constituyen los mecanismos de construcción de la realidad social, mecanismos que definen los contornos de los sistemas de significado, valores y normas y creencias que guían a los sujetos.

En última instancia, uno no puede disociar las representaciones, las prácticas y su discurso, porque constituyen un todo (Martin y Royer-Rastoll 1990). De esta manera, la narración autobiográfica es una parte integral de la acción futura y, como tal, es constitutiva de la realidad social.

\section{La utilidad del relato de sí en la investigación praxeológica}

En la investigación praxeológica, de corte cualitativo, las fases de recopilación, análisis e interpretación de los datos (Ver-Juzgar) están estrechamente vinculadas y no pueden separarse tampoco de la experiencia vital de quien está analizando, reflexiva y críticamente, su propia práctica para transformarla y aprender de ella (Actuar-Devolución creativa). El descubrimiento viene impulsado por la casualidad y luego es guiado por elementos teóricos y procedimientos metodológicos apropiados para lograr nuevos aprendizajes y los cambios deseados para la acción. Desde el punto de vista cualitativo de las ciencias sociales, nuestro enfoque praxeológico se centra en una comprensión (en lugar de en la causalidad) basada en indicadores fenomenológicos y existenciales, abriéndose al descubrimiento de singularidades y reconociendo las particularidades de cada experiencia. El relato de vida es contextualizado y permite el acceso tanto a la experiencia vivida de la persona, como a las limitaciones y potencialidades relacionados con sus entornos vitales.

En la investigación praxeológica rápidamente aparecen formas narrativas: el sujeto que observa y analiza su práctica las utiliza para expresar los contenidos de su experiencia vital. Mediante un trabajo propio de recuperación de la memoria, estos relatos narrativos le permiten describir escenas de su experiencia para explicar las condiciones bajo las cuales actúa, para juzgar su situación como profesional, para vislumbrar lo que debe cambiar en su forma de actuar. Según Bertaux (2005), hay una historia de vida tan pronto como surge una descripción narrativa de un fragmento de la experiencia vivida. En esta perspectiva, el relato de sí enriquece considerablemente la investigación al darle una dimensión diacrónica que permite comprender los contextos sociales en los que uno se encuentra al actuar. Es a través de las muchas pistas contenidas en esa historia de vida que uno puede comenzar a comprender los procesos materiales, sociales, lingüísticos, educativos, culturales e identitarios que han ayudado o dificultado la práctica analizada. 
El relato de sí proporciona simultáneamente información y pistas, en tres niveles principales, sobre fenómenos fundamentales a la hora de analizar e interpretar la propia práctica:

- El nivel individual (actor): el de la interioridad del sujeto (estructuración inicial de su personalidad a través de la socialización y sus primeras experiencias, aprendizaje cultural y profesional, tipo de conducta habitual, entre otros).

- El nivel de las relaciones intersubjetivas: el de la historia de sus relaciones duraderas con sus parientes y amigos, sus maestros, sus redes, alianzas y rivalidades.

- El nivel socio-estructural (sistema): el de las relaciones socio-estructurales propias de este o aquel contexto social y la definición de posiciones, estatutos, roles, normas, creencias, competencias, valores, significados compartidos.

Para la investigación praxeológica, no es necesario extraer de la historia de vida todos los significados que contiene, sino solo aquellos relevantes para analizar e interpretar la práctica en cuestión (índices). En un relato de sí, estas pistas pertenecen a tres órdenes de realidad:

- La realidad histórico-empírica: el camino biográfico que integra la sucesión de situaciones objetivas del sujeto, pero también el modo en que las vivió.

- La realidad psíquica y semántica: lo que el sujeto sabe y piensa retrospectivamente de su recorrido biográfico, en función de su actuar, resultado de lo que el sujeto ha hecho con sus experiencias hasta el momento.

- La realidad discursiva de la historia: correspondiente a lo que el sujeto quiere decir sobre lo que sabe y piensa de su práctica ese momento y a esas personas a las que desea trasmitir su saber praxeológico.

Dado que el relato de sí requiere memoria, reflexividad, juicio moral, aspectos culturales e ideológicos, entre el recorrido biográfico real del sujeto y la narrativa que hace de él al observar y analizar su práctica, hay un nivel intermedio: es la totalización subjetiva de la experiencia vivida. Por eso, la investigación praxeológica requiere reconstruir la estructura diacrónica de la narración biográfica, es decir, la sucesión de eventos significativos con sus relaciones de antes y después; pese a las distorsiones, confusiones, olvidos, inconsistencias e incluso disimulaciones, permite una objetividad al menos discursiva. Este enfoque temporal ayuda a comprender los efectos de la causalidad en la historia de la vida del sujeto, en función de la práctica que analiza: lo que sucedió antes no puede haber sido causado de ningún modo por lo que ocurrió después. Si bien la historia de vida es subjetiva (porque el sujeto colorea su historia con las interpretaciones que hace de su experiencia), su estructura no cambia, incluso con varios años de diferencia. Uno puede cambiar su interpretación de los acontecimientos que está experimentando o de sus explicaciones, pero los eventos serán siempre los mismos en un buen ejercicio de investigación praxeológica. 
Para ello en la investigación praxeológica el relato autobiográfico puede ser trabajado con alguno de las siguientes estrategias:

- Análisis diacrónico: se enfoca en la sucesión de eventos significativos, a lo largo del tiempo, e intenta clarificar la relación antes / después entre ellos.

- El análisis integral: consiste en construir una representación de las relaciones y procesos que están en el origen de los fenómenos narrados.

- El análisis temático: consiste en identificar en cada relato los pasajes que tocan diferentes temas para comparar sus contenidos con la práctica.

- Análisis comparativo: consiste en elaborar progresivamente un modelo cada vez más preciso y rico que muestre recurrencias entre diferentes situaciones.

La investigación praxeológica, que rescata la acción de los sujetos y propone comprender la realidad y/o transformarla (bajo una perspectiva crítica), transformando primero la propia práctica, asume la importancia de lo narrativo, reivindicando una manera diferente de crear saberes, en donde la palabra surge como eje central de la investigación. Así, la investigación praxeológica, en tanto modo epistémico de generar saber, se acerca más a una forma de comprensión de la realidad que de explicación. Pero en este caso la comprensión se plantea en términos de un acto comunicativo. En la escritura biográfico-narrativa que utiliza la investigación praxeológica, el "sujeto que escribe pide comprenderse comprendiendo el mundo, y comprendiéndose comprende lo otro, el otro" (Bolívar 2002: 168).

\section{Referencias bibliográficas}

Bauman, Z. (2007), Vida de consumo. Madrid: Fondo de Cultura Económica.

Beck, U. (2003), La société du risque: Sur le voie d'une autre modernité. París: Flammarion.

Beauvoir, S. de (1967), Memorias de una joven formal. Buenos Aires: Sudamericana.

Bertaux, D. (2005), Los relatos de vida. Perspectiva etnosociológica. Barcelona: Bellaterra.

Bolívar, A. (2002), ¿De nobis ipsis silemus?” Epistemología de la investigación biográfico-narrativa en educación, Revista Electrónica de Investigación Educativa, 4 (1). Recuperado de https://redie.uabc.mx/redie/article/view/49

Cabanes, R. (1996), "El Enfoque biográfico en sociología". Cuadernos del CIDS, Serie II, núm. 1, Bogotá.

Cardano, G. (1991), Mi vida. Madrid: Alianza.

Chanfrault-Duchet, M-F. (1987), "Le récit de vie: donnée ou texte?" en Cahiers de recherche sociologique, vol. 5, núm. 2, Montréal, págs. 11-28.

(1988), "Le système interactionnel du récit de vie", Sociétés. Paris: mayo, págs. 26-31. 
(1995), "Mitos y estructuras narrativas en la historia de vida: la expresión de las relaciones sociales en el medio rural", Historia y Fuente Oral, núm. 9. Barcelona, págs. 12-21.

Cyrulnik, B. (2012), "Préface", en Lani-Bayle, M. y Milet, É. Traces de vie. De l'autre côté du récit et de la résilience. Lyon : Chronique Sociale.

Delory-Momberger, Ch. (2015), La condición biográfica. Ensayos sobre el relato de si en la modernidad avanzada. Medellín: Universidad de Antioquia.

Elias, N. (1990), La sociedad de los individuos. Barcelona: Península.

Foucault, M. (2001), “L'écriture de soi”, Dits et écrits 1954-1988. Paris: Gallimard.

Franzke, J. (1989), "El mito de la historia de vida”, Historia y Fuente Oral, núm. 2. Barcelona, págs. 57-64.

García Márquez, G. (2002), Vivir para contarla. Bogotá: Editorial Norma.

Gide, A. (1956), Si la semilla no muere. Buenos Aires: Losada.

Hadot, P. (2006), Ejercicios espirituales y filosofía antigua. Madrid: Siruela.

Juliao, C. G. (2019), Tomar la filosofía en serio. Aproximaciones praxeológicas al oficio de filosofar. Bogotá: Uniminuto.

Kaufmann, J-C. (1996), L'Entretien compréhensif. París: Nathan.

Lejeune, P. (1971), L'Autobiographie en France. Paris: Armand Colin.

Lenormand, H. R. (1950), Confesiones de un autor dramático. Ediciones Sudamericana. Malraux, A. (1992), Antimemorias. Barcelona: Círculo de Lectores.

Martin, D. y Royer-Rastoll, Ph. (1990), Réprésentations sociales et pratiques quotidiennes. Paris: L'Harmattan.

May, G. (1979), L'Autobiographie. Paris: P.U.F.

Nussbaum, M. (2003), La terapia del deseo: Teoría y práctica de la ética helenística. Madrid: Paidos Ibérica.

Piña, C. (1989), "Sobre la naturaleza del discurso autobiográfico", Argumentos. México: Universidad Autónoma Metropolitana, Campus Xochimilco, núm. 7, págs. 131-160.

Vrancken, D. (1986), "Mémoire de chapeliers: du récit à l'élaboration du mythe", Cahiers internationaux de sociologie, vol. 81, año 33, págs. 315-324.

Zemelman, H. (1997), El futuro como ciencia y utopía. México DF, UNAM. 